www.jmscr.igmpublication.org

Index Copernicus Value: 79.54

ISSN (e)-2347-176x ISSN (p) 2455-0450

crossrefDOI: https://dx.doi.org/10.18535/jmscr/v7i2.68

Journal Of Medical Science And Clinical Research

IGM Publication

An official Publication of IGM Publication

\title{
Perinatal Outcome in High-Risk Pregnancies with and without Meconium Stained Liquor Amnii
}

Authors

\author{
Lt Col (Dr.) Kaoser Jahan', Maj (Dr) Ariful Haque², Dr Lubna Jahan \\ ${ }^{1}$ MBBS, DGO, FCPS (Obst \& Gynae), CMH, Savar, Dhaka \\ ${ }^{2}$ MBBS, DA, FCPS (Anaesthesiology), CMH, Savar, Dhaka \\ ${ }^{3}$ MBBS, FCPS (Obst \& Gynae), Kurmitola General Hospital, Kurmitola, Dhaka
}

\begin{abstract}
Meconium leads to increased sleepiness of fetus in mother's womb. Prevalence of meconium stained amniotic fluid $(M S A F)$ is $12-16 \%$ of all the deliveries. In utero passage of meconium may simply represent the normal gastro intestinal maturation or may indicate an acute or chronic hypoxic event, thereby making it a warning sign of foetal compromise. Fetal assessment and wellbeing has traditionally been evaluated on the basis of fetal movements and color of the amniotic fluid. Presence of meconium in the amniotic fluid has long been considered as ominous sign for fetal distress. Meconium reduces the antibacterial property of amniotic fluid by altering the level of zinc in it which leads to intra amniotic infections. In case of hypoxia, gasping of fetus results in meconium aspiration which neutralizes the surfactant action and promotes inflammation of lung tissues, whereas persistent hypoxia after birth, aspirated meconium results in pulmonary vascular and pulmonary hypertension. Conflicting outcomes have been reported in the deliveries complicated by meconium staining, which differs with the degree of meconium staining.

The aim of this study is to know the association between the meconium stained amniotic fluid and its association with the perinatal outcome.

It is a cross-sectional design was considered suitable for the study. This study was carried out on the admitted patient in the department of Obstetrics and Gynecology, Combined Military Hospital (CMH), Dhaka. The study was carried out during the period from February 2018 to July 2018, 6 months. Total 86 patients who admitted in "high-risk antenatal ward" in the department of Obstetrics and Gynecology to present hospital for delivery with meconium stained liquor during the study period were included in the study. Among sample patients 12 (14.0\%) were found with meconium stained liquor (group A) and 74 (86.0\%) cases were found without meconium stained liquor (group B). In group A common risk factors were prolonged pregnancy (33.3\%) then hypertensive disorder $25.0 \%$. In group B common risk factors were hypertensive disorders $23.0 \%$ then diabetes $18.9 \%$. Pattern of antenatal care was regular in $83.3 \%$ cases in group A which was $83.8 \%$ in group B. Gestational age was between $37-40$ weeks in $50.0 \%$ cases in both group, Gestational age was found $\geq 40$ weeks in $33.3 \%$ cases in group $A$, in comparison to $39.2 \%$ in group $B$. In group A vaginal delivery was $8.3 \%$, LUCS $91.7 \%$ which was $16.2 \%$ and $83.8 \%$ in group B respectively. Still birth was $8.3 \%$ in Group A. In group B Still birth was $1.4 \%$ and neonatal death was $2.7 \%$.Incidence of low birth weight (<2.5 $\mathrm{Kg}$ ) was $33.3 \%$ in group $A$ in comparison to $9.5 \%$ in group B. $27.0 \%$ baby of group A required resuscitation and $45.5 \%$ needed admission in neonatal care unit which was $8.2 \%$ and $16.4 \%$ in group $B$ respectively. Among the study population $(n=86)$ babies were found without complication $83.7 \%$, still birth 2.3\%, meconium aspiration $1.2 \%$, birth asphyxia $10.5 \%$ and neonatal death was $2.3 \%$.

In this study, it was observed that perinatal mortality was not directly related to meconium aspiration syndrome rather premature separation of placenta, placental insufficiency, prematurity \& low birth weight were the main association. Present study showed that thick meconium is associated with more complications like increased operative interference, birth asphyxia, meconium aspiration syndrome, low Apgar score, prolonged NICU stay and overall increased perinatal mortality compared to thin meconium stained liquor.

Keywords: MAS (meconium aspiration syndrome), MSAF (meconium stained amniotic fluid), NICU (neonatal intensive care unit).
\end{abstract}




\section{Introduction}

The nearness of meconium recolored amniotic liquid (MSAF) is a genuine indication of foetal compromise, which is related with an expansion in perinatal morbidity ${ }^{[1,2]}$ clear amniotic fluid on the other hand is considered reassuring. Presence of MSAF is seen in 12-16\% of deliveries ${ }^{[3]}$. Inutero, passage of meconium may simply represent the normal gastrointestinal maturation or it may indicate an acute or chronic hypoxic event, thereby making it a warning sign of a foetal compromise. Meconium passage is rare before 34 weeks of gestation and incidence increases steadily beyond 37 weeks of gestation ${ }^{[4]}$. Factors such as placental insufficiency, maternal hypertension, pre-eclampsia, oligohydramnios or maternal drug abuse (tobacco, cocaine) result in in-utero passage of meconium ${ }^{[5]}$.

Meconium is thick, dark green, sticky tar-like substance containing mucus, bile, epithelial cells that are passing as baby's first bowel motion. At times this can be passed before baby's birth discoloring water. It is often used the term "mec" or "mec-stained liquor" (written as MSL).It complicates about $15 \%$ of all pregnancy. Meconium stained liquor categories into three grades, namely grade I (light), grade II (moderate), grade III (heavy).

Meconium stained liquor categories into three grades-

Grade I (light): Light meconium staining is when there is small amount of meconium diluted in a plentiful amount of amniotic fluid. This gives the waters only a slight, greenish or yellowish tinge or discoloration. A slight discoloration is generally not a concern and the baby could have passed it any time during the last weeks of pregnancy. It is usually not related to distress in labor and will usually not cause meconium aspiration syndrome.

Grade II (moderate): Moderate meconium staining is when there is a fair amount of amniotic fluid, but it is clearly stained with meconium. In this case the waters will definitely look greenish or brownish in color. Moderate meconium staining is a possible sign of fetal distress for the baby. This would be confirmed with abnormal or low heart rates in the baby. Moderate meconium passed early in the labor can be more of concern, than if noticed towards the end, near the birth. This is because the baby is suspected of being distressed before having to deal with the labor to come. That is also a concern that the baby could inhale the meconium at birth, with a risk of Meconium, Aspiration Syndrome (MAS).

Grade III (heavy): Heavy meconium staining is when there is reduced amniotic fluid and a large amount of meconium, making the staining quite thick. This is often likened to "pea soup". The waters are more like a thick, green, oozy discharge rather than a watery flow and can be very dark green or black in color.

Infants born through MSAF are about 100 times more likely to develop respiratory distress than those which are born through clear fluid ${ }^{[6]}$. Even in women who are at very low risk for obstetric complications, MSAF is common and it is associated with a five-fold increase in perinatal mortality as compared with low-risk patients with clear amniotic fluid. Presence of meconium below vocal cord is known as meconium aspiration and it is seen in around 20-30 \% of all infantswith $\mathrm{MSAF}^{[7]}$. Aspiration can beoccurred in-utero with foetal gasping, or after birth, with the first breaths of life. Meconium aspiration syndrome (MAS) is defined as a respiratory distress that develops shortly after birth, with radiographic evidence of aspiration pneumonitis and presence of MSAF ${ }^{[8]}$. MAS occurin about $5 \%$ of deliveries with MSAF and death occurs in about $12 \%$ of infants with $\operatorname{MAS}^{[9]}$.

Meconium in utero is associated with a poor perinatal outcome such as low Apgar score, chorioamnionitis, increased rate of Neonatal intensive care unit (NICU) admission and perinatal death. Meconium passage is a normal event programmed within first 24-48 hours after delivery. Fetomaternal stress factors like hypoxia and infection lead to meconium passage in utero in near term foetuses, leading to perinatal morbidity and mortality ${ }^{[10]}$. Even though the 
meconium appears very early in the foetal intestine in utero, it is not seen in amniotic fluid before 38 weeks of gestation age. Detection of MSAF is associated with abnormal FHR, so once the MSAF is detected, continuous FHR monitoring is needed as is associated with abnormal foetal outcome. Meconium aspiration into the neonatal lungs is associated with clinical entities ranging from respiratory distress to severe respiratory compromise thus leading to significant increase in perinatal morbidity and mortality ${ }^{[11]}$.

MSAF is associated with both maternal and foetal risk factors. Maternal factors include hypertension, gestational diabetes mellitus, maternal chronic respiratory or cardiovascular diseases, post term pregnancy, pre-eclampsia and eclampsia. Foetal factors include oligohydramnios, foetal growth restriction and poor bio physical profile ${ }^{[\mathbf{1 2}]}$. MSAF is associated with increased risk of operative interference in terms of instrumental delivery or caesarean section and increased rate of neonatal resuscitation and meconium aspiration syndrome (MAS) ${ }^{[13]}$.

This study was carried out to know the correlation of MSAF with perinatal outcome, also, to know the difference between thin and thick MSAF on fetal outcome and in relation with stage and mode of delivery and antenatal complications.

\section{Objectives}

1. To evaluate the perinatal outcome in term pregnancies with meconium stained amniotic fluid.

2. To bring out the correlation between fetal heart rate abnormalities and perinatal outcome inmeconium stained amniotic fluid.

\section{Materials and Methods}

Study design: A cross-sectional design was considered suitable for the study.

Place of Study: This study was carried out on the admitted patient in the department of Obstetrics and Gynecology, Combined Military Hospital (CMH), Dhaka.

Period of Study: The study was carried out during the period from February 2018 to July 2018, 6 months.

Study population: The sample was collected from women who were admitted in "high-risk antenatal ward" at $\mathrm{CMH}$, Dhaka during the study period.

\section{Inclusion criteria}

- High-risk pregnancies with or without meconium stained liquor.

- High-risk pregnancies: Identified by following criteria (WHO, 1978):

Elderly primi ( $\geq 30$ years), short statured primi ( $\leq$ $140 \mathrm{~cm})$, threatened abortion and APH, malpresentation, preeclampsia, eclampsia, anemia, elderly grandmultiparas, twin and hydramnios, previous stillbirth, IUD, manual removal of placenta, prolonged pregnancy, previous caesarean section and instrumental delivery, pregnancy with medical diseases, PROM, prolonged labor, hand, feet or cord prolapse, placenta retained more than a half an hour, PPH, puerperal fever or sepsis.

Exclusion criteria: Congenital anomaly of baby (diagnosed antenatally by USG or diagnosed during or after delivery).

Sample size: Total 86 patients who admitted in "high-risk antenatal ward" in the department of Obstetrics and Gynecology, CMH, Dhaka were enrolled for this study.

Sample size determination: The sample size was determined by following formula

$$
n=\left(Z^{2} \times p \times q\right) / d^{2}
$$

Where,

$\mathrm{z}=1.96$ (Value of standard normal distribution).

$\mathrm{p}=0.2(20 \%$ prevalence $)$

$\mathrm{q}=(1-\mathrm{p})=0.8$

$\mathrm{d}=$ acceptable error $=0.085$

From the formula calculated sample size $=86$

Variables studied

(1) Neonatal outcome

a) Status of child at birth 
Dead or alive

If alive degree of asphyxia (or APGAR score)

Resuscitation needed - yes/no

b) Any other complication

(2) Neonatal factors associated with meconium stained liquor.
a) Birth weight of the baby
b) Sex of the baby
c) Duration of gestation.
d) Length of cord.
e) Cord around the neck.

(3) High-risk factors commonly associated with meconium stained liquor.

\section{Operational definition}

Perinatal period: For the study perinatal period was taken as : From the time of delivery till discharge form hospital.

Flow chart showing sequences of tasks:

Month 1 Planning and preparation.

Month 2-5 Data collection and analysis.

Month 6 Report writing and submission to BCPS.

Ethical consideration: The aims and objectives of the study were explained to the patients in easily understandable local language and then consent was taken from each patient. It was assured that all actions and records would be kept confidential.

Method of data collection: After discussing the patient and getting consent from patient a detailed history was taken, regarding obstetrical, menstrual, medical, and surgical. Physical examination was done relevant investigation recorded.

Detailed history was taken regarding any known medical disorder, abortion, caesarean section, age of the patient, any stillbirth, IUD.
Physical examination was done. Height of the patients, anemia, jaundice, BP, edema, fundal height, FM, FHR was recorded.

Patients were followed up closely during intrapartum and post-partum period, all the important events were recorded including mode of delivery, nature of liquor (whether meconium stained or not). Neonatal details considering sex of baby, weight of the baby, APGAR score, baby resuscitation, cord around the neck (detected during delivery), cord length recorded. Both mother and neonate followed up to discharge from hospital. All the necessary information was recorded in data collection sheet.

Patient having meconium stained liquor was labeled as group A and without meconium stained liquor was labeled as group B.

Quality control: After collection, data were checked for inadequacy, irrelevancy and inconsistency. Irrelevant and inconsistent data were discarded.

Data analysis: All data were processed and analyzed by using computer based statistical Software.

\section{Limitation of the study}

1) Fetal scalp blood PH study and fetal blood sampling were not possible at $\mathrm{CMH}$, Dhaka.

2) Neonates were followed up upto the discharge from hospital; therefore, actual number of neonatal morbidity and mortality could not be detected.

3) Study was carried out in a small group of population in a Military Hospital where treatment is free of cost. As such, outcome of this study does not reflect the entire picture of Bangladesh.

\section{Results}

Table I: Risk scoring of the study population $(n=86)$

\begin{tabular}{|l|c|c|}
\hline Risk Group & Number of Patients & Percentage \\
\hline High-risk Pregnancy & 78 & 90.7 \\
\hline Severe High-risk Pregnancy & 8 & 9.3 \\
\hline Total & $\mathbf{8 6}$ & $\mathbf{1 0 0 . 0}$ \\
\hline
\end{tabular}

Table I shows among the 86 cases high-risk pregnancy was 78(90.7\%) and severe high-risk pregnancy was 8 $(9.3 \%)$. 


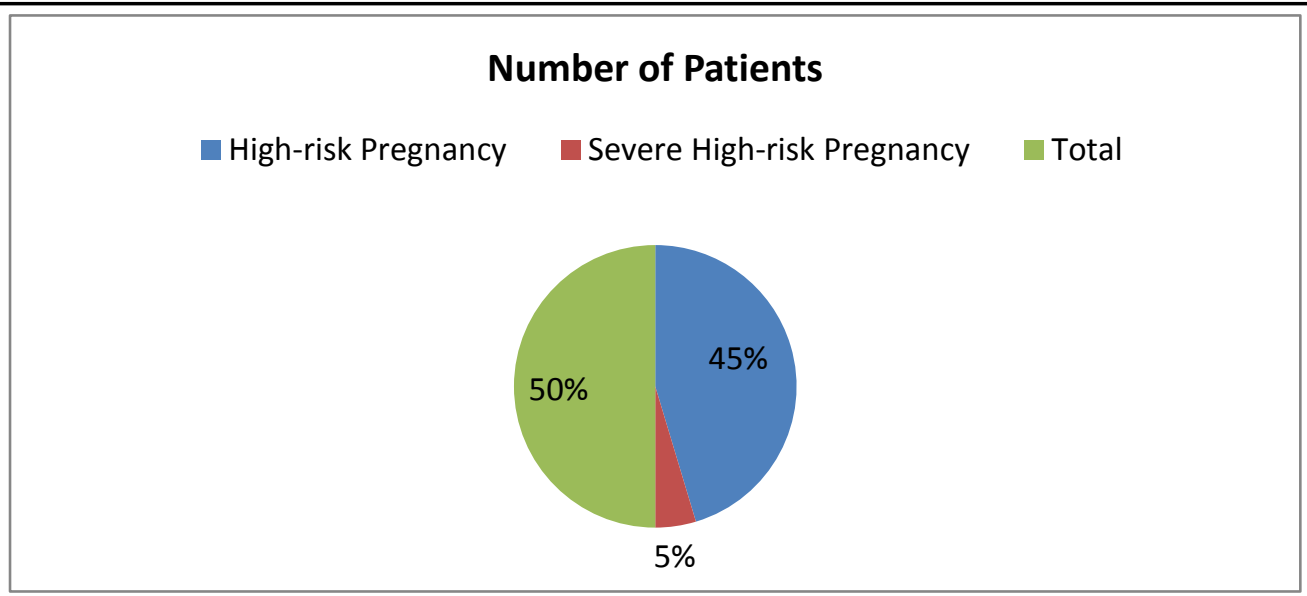

Figure I: Pie chart of risk scoring of the study population

Table II: Association of meconium stained liquor in relation to risk scoring $(n=86)$

\begin{tabular}{|l|c|c|c|}
\hline Risk groups & Group A $(\mathrm{n}=12)$ & Group B $(\mathrm{n}=74)$ & p value \\
\hline High risk pregnancy & $9(11.5)$ & $69(88.5)$ & 0.079 \\
\hline Severe high-risk pregnancy & $3(37.5)$ & $5(62.5)$ & \\
\hline Total & $\mathbf{1 2}(\mathbf{1 4 . 0})$ & $\mathbf{7 4}(\mathbf{8 6 . 0})$ & \\
\hline
\end{tabular}

Table II shows that out of 78 patients in high-risk $(62.5 \%)$ in group B. Total number of patient with pregnancy group $9(11.5 \%)$ in group A, 69 meconium stained liquor was $12(14.0 \%)$ and $(88.5 \%)$ in group B. In severe high-risk pregnancy without meconium stained liquor was $74(86.0 \%)$. group $3(37.5 \%)$ in group $\mathrm{A}$ in comparison to 5

The parameters are taken in an aim to compare the prenatal outcome with-

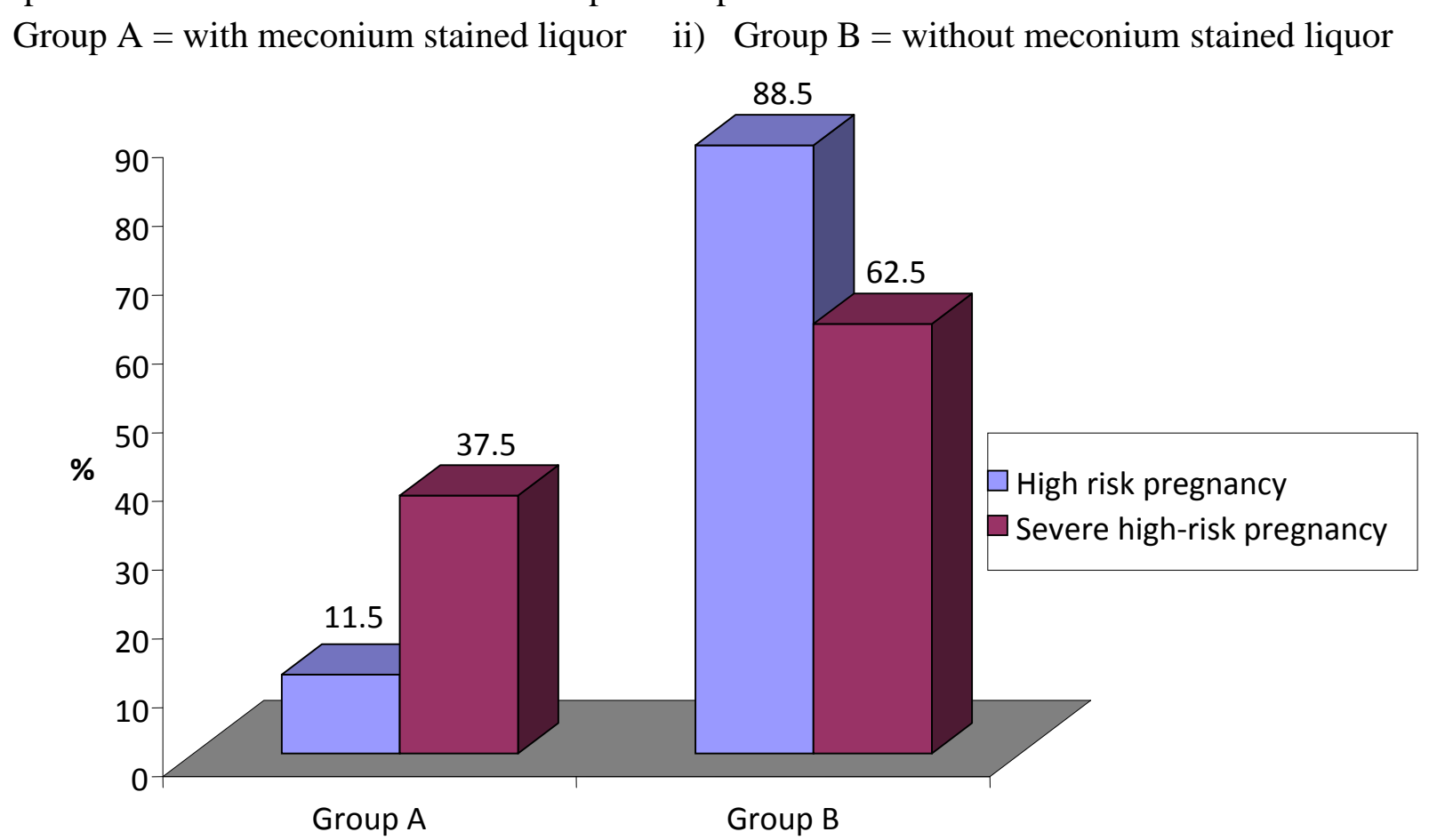

Figure II: Bar diagram of association of meconium stained liquor in relation to risk scoring 
Table III: Risk factors associated with and without meconium stained liquor

\begin{tabular}{|l|c|c|c|}
\hline Risk Factors & Group A & Group B & p value* \\
\hline Hypertensive disorders & $3(25.0)$ & $17(23.0)$ & 0.999 \\
\hline Diabetes & $2(16.7)$ & $14(18.9)$ & 0.999 \\
\hline Prolonged pregnancy & $4(33.3)$ & $12(16.2)$ & 0.224 \\
\hline Previous caesarean section & $1(8.3)$ & $10(13.5)$ & 0.999 \\
\hline PROM & $2(16.7)$ & $6(8.1)$ & 0.309 \\
\hline Malpresentation & $0(.0)$ & $6(8.1)$ & 0.306 \\
\hline Other medical disorders & $0(.0)$ & $9(12.2)$ & 0.348 \\
\hline
\end{tabular}

*Fisher's Exact test was done to measure the level of significance.

Table III shows risk factors associated in group A were prolonged pregnancy 4 (33.3\%), hypertensive disorders 3 (25.0\%), diabetes 2 (16.7\%), PROM 2 (16.7\%) and previous caesarean section $1(8.3 \%)$. On the other hand, in Group B hypertensive disorder was 17 (23.0\%), diabetes $14(18.9 \%)$, prolonged pregnancy 12 (16.2\%), previous caesarean section 10 (13.5\%)), other medical disorders 9 (12.2\%), PROM and malpresentation were $6(8.1 \%)$ \& $6 \quad(8.1 \%)$ respectively.

Table IV: Pattern of antenatal care

\begin{tabular}{|lccc|}
\hline Antenatal Care & Group A & Group B & p value* \\
\hline Regular & $10(83.3)$ & $62(83.8)$ & 0.999 \\
Irregular & $2(16.7)$ & $12(16.2)$ & \\
Total & $\mathbf{1 2}(\mathbf{1 0 0 . 0})$ & $\mathbf{7 4}(\mathbf{1 0 0 . 0})$ & \\
\hline
\end{tabular}

*Fisher's Exact test was done to measure the level of significance.

Table IV shows $10(83.3 \%)$ patient in group A regular antenatal care \& 12(16. 2\%) were on were on regular antenatal care and $2(16.7 \%)$ were irregular antenatal care.

on irregular care. In group B $62(83.8 \%)$ were on

Table V: Duration of gestation

\begin{tabular}{|l|c|c|c|}
\hline Duration of gestation in week & Group A & Group B & p value* \\
\hline $28-<34$ & $1(8.3)$ & $3(4.1)$ & 0.911 \\
\hline $34-<37$ & $1(8.3)$ & $5(6.8)$ & \\
\hline $37-40$ & $6(50.0)$ & $37(50.0)$ & \\
\hline$>40$ & $4(33.3)$ & $29(39.2)$ & \\
\hline Total & $\mathbf{1 2 ( 1 0 0 . 0 )}$ & $\mathbf{7 4 ( 1 0 0 . 0 )}$ & \\
\hline
\end{tabular}

Table $\mathrm{V}$ shows in group A gestational age was between $37-40$ weeks in $6(50.0 \%),>40$ weeks in $4(33.3 \%)$ between $28-<34$ weeks in $1(8.3 \%)$ and between $34-<37$ weeks in $1(8.3 \%)$ patient.
In group B gestational age was between $37-40$ weeks in $37(50.0 \%)$, > 40 weeks in $29(39.2 \%)$, between $34-<37$ weeks in $5(6.8 \%)$ and between $28-<34$ weeks. in $3(4.1 \%)$.

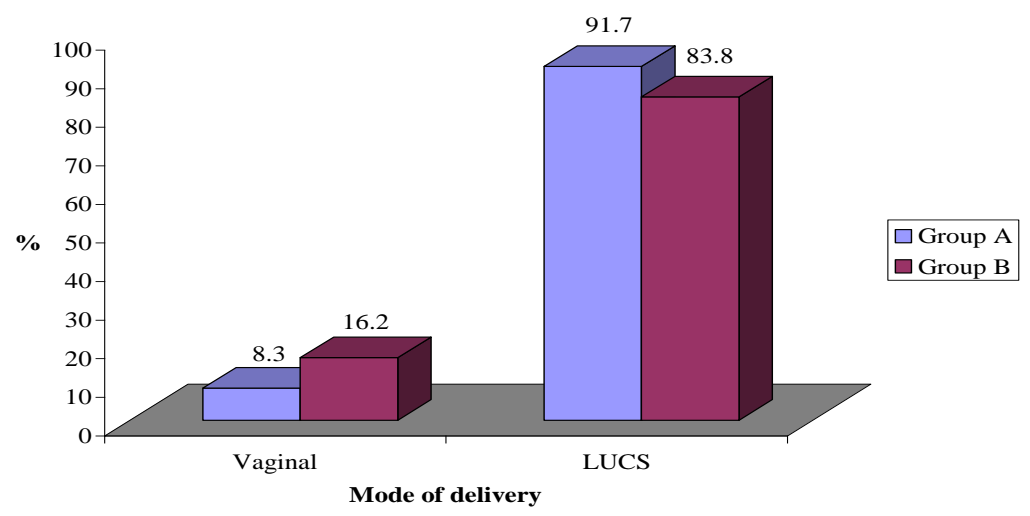

Figure III: Bar diagram of mode of delivery 
Bar diagram shows patient in group A $1(8.3 \%)$ patient delivered vaginally in comparison to 12 (16.2\%) patient in group B. Mode of delivery was

Table VI: Perinatal mortality in relation to meconium stained liquor

\begin{tabular}{|l|c|c|c|}
\hline Perinatal mortality & Group A & Group B & p value* $^{*}$ \\
\hline Stillbirth & $1(8.3)$ & $1(1.4)$ & 0.261 \\
\hline Neonatal death & $0(.0)$ & $2(2.7)$ & 0.999 \\
\hline
\end{tabular}

*Fisher's Exact test was done to measure the level of significance.

Table VI shows stillbirth was $1(8.3 \%)$ in group A and $1(1.4 \%)$ in group B, neonatal death was 2
LUCS in group A and group B was $11(91.7 \%) \&$ $62(83.8 \%)$ respectively.

Table VII: Cord around neck of the baby and percentage

\begin{tabular}{lcc}
\hline Amniotic fluid & \multicolumn{2}{c}{ Cord around the neck of the baby } \\
\cline { 2 - 3 } & No of patient & Percentage \\
\hline Meconium Stained $(\mathrm{N}=12)$ & 3 & 25 \\
Without meconium $(\mathrm{N}=74)$ & 6 & 8.1 \\
\hline
\end{tabular}

Table VII shows 3 (25\%) babies were found with Cord around the neck of the baby causing cord cord around neck in group A in comparison to 6 compression which causes hypoxia and increase $(8.1 \%)$ in group B. vagal response, ultimately causes relaxation of anal sphincter and passage of meconium.

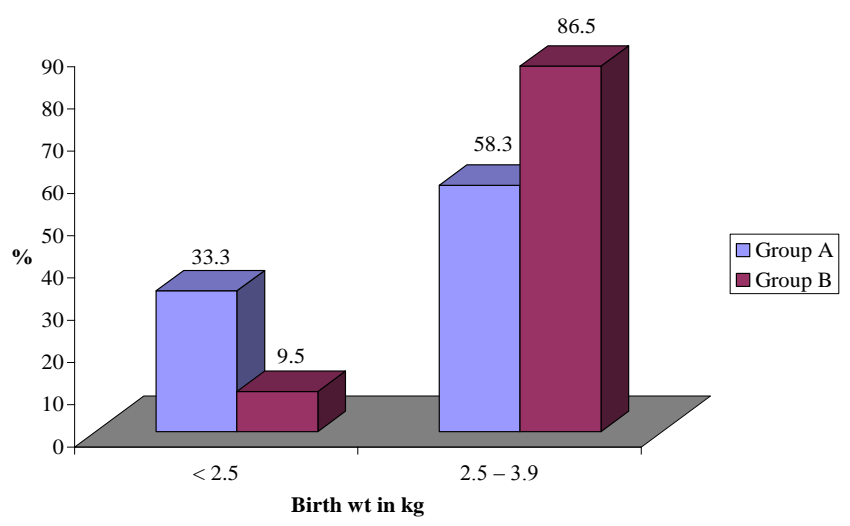

Figure IV: Bar diagram of birth weight of the babies

Bar diagram shows in group A birth wt $<2.5 \mathrm{~kg}$ in $4(33.3 \%),(2.5-3.9) \mathrm{kg}$ in $7(58.3 \%)$ and $\geq 4 \mathrm{~kg}$ in
$1(8.3 \%)$ and in group B $<2.5 \mathrm{~kg}$ in $7(9.5 \%)$, $(2.5-3.9) \mathrm{kg}$ in $64(86.5 \%)$ and $\geq 4 \mathrm{~kg}$ in $3(4.1 \%)$.

Table VIII: Perinatal complication

\begin{tabular}{|lcc|}
\hline Outcome & Number of Patient & Percentage \\
\hline No complication & 72 & 83.7 \\
complication & 14 & 16.3 \\
\hline
\end{tabular}

Table IX: Perinatal outcome in study population $(n=86)$

\begin{tabular}{|lcc|}
\hline Perinatal outcome & Number of Patient & Percentage \\
\hline Still Birth & 2 & 2.3 \\
Meconium aspiration & 1 & 1.2 \\
Birth asphyxia & 9 & 10.5 \\
Neonatal death & 2 & 2.3 \\
Without complication & 72 & 83.7 \\
\hline
\end{tabular}

Table IX shows among $(\mathrm{n}=86)$ the study birth asphyxia $9(10.5 \%)$ and neonatal death 2 population overall perinatal outcome was still birth $2(2.3 \%)$, meconium aspiration $1(1.2 \%)$, (2.3\%). $72(83.7 \%)$ babies were without complication. 


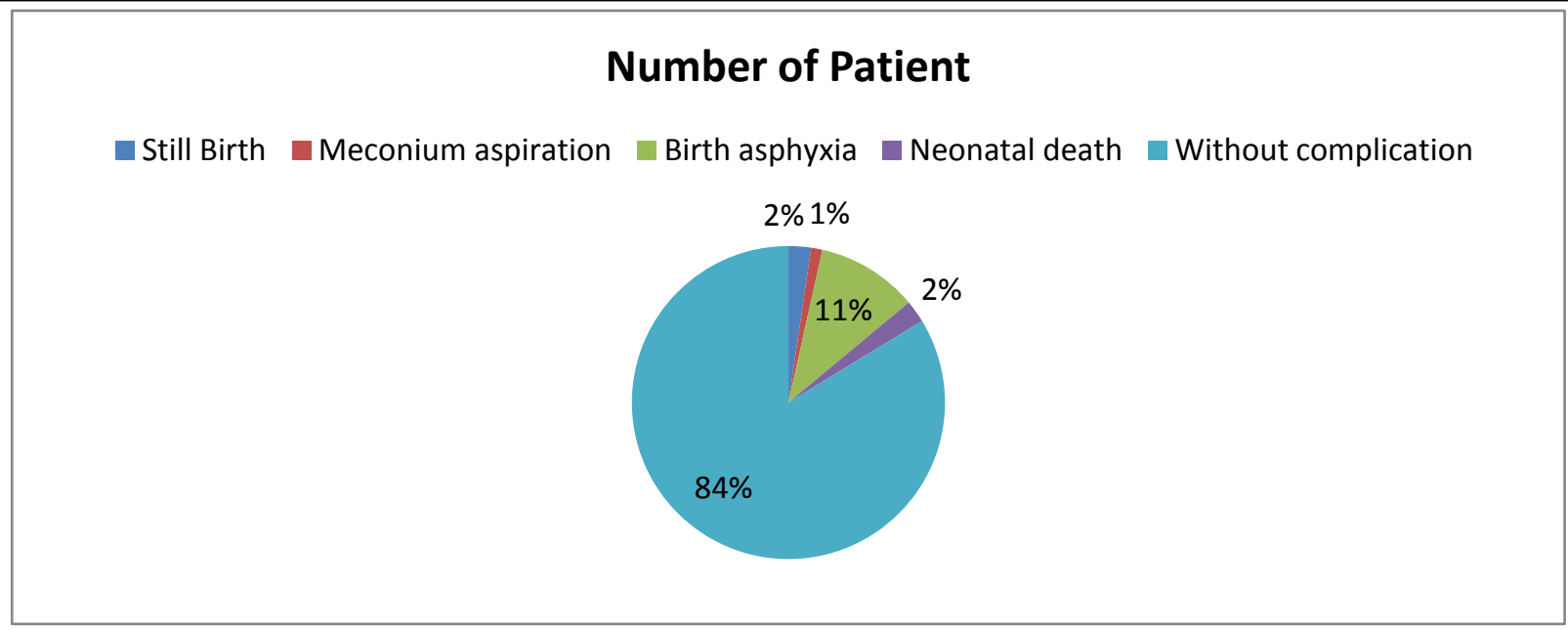

Figure V: Pie chart of perinatal outcome in study population

\section{Discussion}

High-risk pregnancy is one in which mother, fetus or newborn is or may possibly at increased risk of morbidity or mortality, before, during or after delivery. Perinatal outcome is thought to be more adverse when liquor stained by meconium, because meconium stained liquor is generally interpreted as one sign of baby possibly unwell or distressed when inside the uterus, other health concern is meconium aspiration syndrome.

There are limited data available regarding effect of meconium on perinatal outcome in our country. But a comparative study between perinatal outcome in high-risk pregnancy with meconium stained liquor and perinatal outcome in high risk pregnancies without meconium stained liquor has not been studied yet. Present study was undertaken to find out and compare perinatal outcome in high-risk pregnancies with meconium stained liquor (group A) and without meconium stained liquor (group B). In present study, WHO criteria have been used to identify high-risk cases. Table I shows risk-scoring of study population $(\mathrm{n}=86)$ developed by Coopland et al (1977) . 90.7\% patient was in high-risk group and 9.3\% patient was found in severe high risk group. This was well supported by Afroza's study, in her study is was $85 \%$ and $15 \%$ respectively

Among study population ( $\mathrm{n}=86) 12 \quad(14.0 \%)$ patient was found with meconium stained liquor amnii.
Table III shows in group A prolonged pregnancy was associated in $33.3 \%$ cases then hypertensive disorder $25.0 \%$ cases, In Bhatia et al. (2007) in his study showed meconium stained amniotic fluid was in postdated pregnancy $32.4 \%$ cases and preeclampsia $13.9 \%$ cases. In group B hypertensive disorders associated in $23.0 \%$ cases then diabetes in $18.9 \%$ cases.

Table IV shows $83.3 \%$ patient was in regular antenatal care in group A which was $83.8 \%$ in group B.

In Table V, Gestational age 37-40 weeks was in $50.0 \%$ cases in group A which was similar in group B.

Figure III shows in group A vaginal delivery was $8.3 \%$ and LUCS $91.7 \%$. Irin in her study showed, vaginal delivery in meconium stained baby was $22.0 \%$ and LUCS in $78.0 \%$, in group B mode of delivery was vaginal in $16.2 \%$ and LUCS in $83.7 \%$. Here difference of mode delivery between two groups was significant. Higher rate of LUCS in group A was mainly due to previous LUCS, fetal distress and associated medical disorders.

Table VI shows, in present study stillbirth was $8.3 \%$ in group $\mathrm{A}$ in comparison to $1.4 \%$ in group B, Neonatal death was $2.7 \%$ in group B. In group A, stillbirth was due to abruption placenta, consequence of hypertension. In group B stillbirth was due to chronic placental insufficiency consequences of various medical disorders. In group B neonatal death was due to low birth weight, prematurity. 
Perinatal mortality in group A was $8.3 \%$. In Irin's study it was $4.0 \%$, it is significant may be due to study population of present study was high-risk cases having one or more co-morbiding which played significant role in perinatal mortality. It was observed that in group A, perinatal mortality was due to abruptio placenta (premature separation of placenta), low birth weight, prematurity but was not directly related to meconium aspiration syndrome.

Overall perinatal mortality among study population ( $\mathrm{n}=86$ ) was $4.6 \%$ this is well supported by Y. Malik, Nisar's study. Y Malik in his study showed that perinatal mortality in high risk population is $4.0 \%$.

Table VII shows in group A $25 \%$ baby had cord around the neck in comparison to $8.10 \%$ in group B. So, meconium stained liquor has a strong association with cord around neck of baby but cord around neck not always causes meconium stained liquor.

Table IX shows in group A alive baby was 11 and stillbirth 1. Among the lived babies $27.0 \%$ babies required resuscitation and $45.5 \%$ required admission in neonatal care unit. In group B total live birth was 73 and stillbirth was 1 . Among the live birth $8.2 \%$ required resuscitation and $16.4 \%$ required admission in neonatal care unit. Neonatal admission in group A was higher due to birth asphyxia and low birth weight.

Present study showed, among study population $(\mathrm{n}=86) \quad 83.7 \%$ baby was without complication, $10.5 \%$ having birth asphyxia, 2.3\% still birth, $1.2 \%$ meconium aspiration and $2.3 \%$ neonatal death,. Main causes of neonatal death were prematurity, low birth weight.

This study showed $93.0 \%$ mother was without complication, 3.5\% had PPH, 2.3\% perinatal tear and $1.2 \%$ had DIC. Maternal mortality was nil.

Present study showed meconium stained liquor amnii is associated with higher rate of LUCS, fetal distress, low Apgar score, low birth weight. Eriksen et al, (1994) in his study showed presence of meconium is associated with higher incidence of abnormal labor, fetal distress, intervention in delivery and low Apgar score. This study is well supported by Eriksen's study.

\section{Conclusion}

Meconium stained amniotic fluid is really worrisome from both obstetrician's and pediatrician's point of view. Based on our study we conclude that meconium stained amniotic fluid is associated with increased incidence of caesarean section, birth asphyxia, neonatal nursery admissions and meconium aspiration syndrome (MAS). So, presence of MSAF requires intensive foetal monitoring in order to decrease perinatal morbidity and mortality.

Presence of meconium in the amniotic fluid during labor often causes anxiety in delivery room because it is assumed as an indicator of poorfetal outcome. Fetal statusduring labor is usually assessed by measuring the fetal heart rate abnormalities and checking the color of the amniotic fluid. It is often assumed that fetal heart rate abnormalities, especially in the presence of meconium stained liquor which indicates hypoxia and acidosis.

Passage of meconium may be a normal physiological event reflecting fetalmaturity. It also reflects fetal hypoxia or increased vagal activity from cord compression. The presence of meconium during labor is associated with an increased risk of perinatal mortality and morbidity. Most workers showed there is an association with fetal heart rate abnormalities, low Apgar scores and low arterial cord $\mathrm{PH}$ in the presence of meconium stained amniotic fluid. The present study was undertaken to evaluate the significance of meconium stained amniotic fluid and its fetal outcome inparturient admitted to the hospitals.

In order to improve perinatal outcome at national level decentralization of $\mathrm{MCH}$ care, extension of EOC coverage, increased intensive neonatal care unit are essential. These high-risk cases need to manage by joint action of obstetrician, anesthesiologist and neonatologist. 


\section{References}

1. Berkus MD, Langer O, Samuelloff A, Xenakis EM, Field NT, Ridgeway LE. Meconium stained amniotic fluid: increased risk for adverse outcome. Obstet Gynecol 1994; 84: 115-20.

2. Nathan L, Leveno KJ, Camody TJ 3rd, Kelly MA, Sherman ML. Meconium: a1990s perspective on an old obstetric hazard. Obstet Gynecol 1994; 83: 329-32.

3. Maymon E, Chaim W, Furman B, Ghezzi F, ShohamVardi I, Mazor M. Meconium stained amniotic fluid in very low risk pregnancies at term gestation. EurJ Obstet Gynecol Reprod Biol. 1998; 80: 169-73.

4. Steer PJ, Eigbe F, Lissauer TJ, Beard RW. Interrelationships among abnormal cardiotocograms in labor, meconium staining of the amniotic fluid, arterialcord blood pH, and Apgar scores. Obstet Gynecol. 1989;74:715-21.

5. Shaikh EM, Mehmood S, Shaikh MJ. Neonatal outcome in meconium stainedamniotic fluid- One year experience. J Pak Med Assoc. 2010;60(9):711-14.

6. Fleischer A, Anyaegbunam A, Guidetti D, Randolph G, Merkatz IR. A persistent clinical problem: profile of the term infant with significant respiratorycomplications. Obstet Gynecol. 1992;79:185-90.

7. Wiswell TE, Bent RC. Meconium staining and the meconium aspiration syndrome. Unresolved issues. PediatrClin North Am. 1993;40:955-81.

8. Klinger M C, Kruse J. Meconium aspiration syndrome: pathophysiology andprevention. J Am Board Fam Med.1999;12(6).

9. Cleary GM, Wiswell TE. Meconiumstained amniotic fluid and the meconiumaspiration syndrome. An update. Pediatr Clin North Am. 1998;45:511-29.

10. Qadir S, Jan S, Chachoo JA, Parveen S. Perinatal and neonatal outcome in meconium stained amniotic fluid. Int $\mathbf{J}$ Reprod Contracept Obstet Gynecol. 2017;5(5):1400-5.

11. Mukhopadhyay PN, Naskar T, Dalui R, Hazra S, Guin K. Role of intrapartumamnioinfusion in meconium stained amniotic fluid, J ObstetGynaecol India. 2006;56(3):230-2.

12. Hackey WE. Meconium Aspiration. In: Gomella TL, ed. Neonatology. 4th ed. New York: Lange Medical Books; 1999:507.

13. Shaikh EM, Mehmood S, Shaikh MA. Neonatal outcome in meconium stained amniotic fluid-one year experience. J Pak Med Assoc. 2010;60:711-4. 